Wonderful by Schneider, 1987). Virtually every film that has depicted ECT or psychosurgery has done so in a destructive fashion (Gabbard \& Gabbard, 1987); recent examples include One Flew Over the Cuckoo's Nest (1975) and Frances (1982). Behavioural therapy is used to abolish 'antisocial' thoughts in A Clockwork Orange (1971). In Dead of Winter (1987) distorted filming and sound convey a terrifying image of sedation. In I'm Dancing As Fast As I Can (1982) a psychiatrist turns his patient into a diazepam addict.

Children's films are not immune from references to ECT (Hodgkinson, 1986). In Walt Disney's Return to $\mathrm{Oz}(1985)$ Dorothy is taken to an 'asylum' by her aunt to get treatment to make her forget $\mathrm{Oz}$. To a background of sinister music the doctor explains that 'electrical treatment' is needed. Dorothy is strapped to a trolley and wheeled to the ECT room. She escapes but is pursued by a nurse. When she enquires about screams she can hear she is told "they're patients who've been damaged, they're locked in the cellar". In $\mathrm{Oz}$ the doctor and nurse reappear as the evil king of the gnomes and the wicked witch.

Nurses often appear as accomplices of the villainous psychiatrist. In Frances (1982) nurses accept bribes to allow soldiers to rape a female patient, lie to patients about the medication they are being given and are seen spoiling for a fight. Not surprisingly, psychiatric hospitals appear as squalid prisons with locked doors, high walls and fences, while compulsory detention is seen as a punishment arbitrarily dealt out according to the psychiatrist's whim.

\section{Clinical relevance}

Unfavourable stereotyping is not unique to psychiatry, film has no obligation to mirror reality and within the Dr Evil stereotype there is some truth; psychiatry has had many scandals regarding patient care. No doubt on an individual basis callous psychiatrists also exist. However the fact remains that Dr Evil is a gross misrepresentation of the average psychiatrist.

Unfortunately this stereotype may prejudice public opinion, film being the closest contact many will have with the profession. For example a survey of lay attitudes to ECT (O'Shea \& McGennis, 1983) indicated public hostility to ECT and a tendency to accept adverse publicity without questioning it. In particular, the majority who had seen One Flew Over the Cuckoo's Nest (1975) reported being "put off ECT" by the film. At an unconscious level assimilated images from the Dr Evil genre may be detrimental to doctor-patient relationships; this may be particularly relevant within psychotherapy. At a more overt level, the content of psychopathology in the mentally ill may be influenced. For example, psychotic patients may be more likely to incorporate psychiatric staff into their persecutory delusions; the negative effects on treatment are obvious. It is ironic that in his film debut (The Cabinet of Dr Caligari, 1919) Dr Evil was portrayed as part of the delusional system of an asylum patient.

Why has Dr Evil had such a successful screen career? Perhaps he reflects a deep-seated public unease about psychiatrists, in particular that they might have the disturbing ability 'to read minds and analyse behaviour and motives'. The 'eccentric quack' and Dr Wonderful, cinema's other psychiatrist stereotypes, could be regarded as alternative defences to cope with this disquieting thought; the former by ridicule, the latter by idealisation. As films are made primarily for profit, winning formulas tend to persist. For this reason alone Dr Evil is likely to remain a stock character for some time. On a constructive level, a knowledge of the stereotype may help psychiatrists understand some of the apprehensions patients and their families have about psychiatric care.

\section{References}

GABBARD, K. \& GABBARD, G. O. (1987) Psychiatry and the Cinema. Chicago: University of Chicago Press.

HodGKInson, J. (1986) ECT and the media (letter). Bulletin of the Royal College of Psychiatrists, 10, 37.

O'SHEA, B. \& MCGENNIS, A. (1983) ECT: lay attitudes and experiences - a pilot studt. Irish Medical Journal, 76, 40-43.

SCHNEIDER, I. (1987) The theory and practise of movie psychiatry. American Journal of Psychiatry, 144, 996-1002.

\title{
The times
}

\section{Re-launch of Bekhterev Journal}

The Bekhterev Journal was founded in 1896 in St Petersburg by V. M. Bekhterev and, with two inter- vals, existed until 1930. Its title was modified several times and in $1927 \mathrm{it}$ was given the name of its founder. 
The Editorial Board intends that the re-launch of the Journal will follow Bekhterev's precept of the necessity of the comprehensive study of man. They also feel the urgent need for the restitution of the humane and civilised attitude to the mentally ill which was characteristic of Russian psychiatry historically.

The increasing level of family problems and divorce in the USSR, the growing number of neurotic disorders and suicide, the self-destructive behaviour of adolescents, alcoholism, drug and substance abuse, prostitution among the young, and early forms of mental disturbance and their treatment need to be brought to the attention of psychiatrists, psychotherapists and psychologists. The Journal is therefore intended for a wide readership both professional and non-professional interested in psychiatry, psychology and allied disciplines. It is felt that much of the material to be published may be of interest to an overseas readership also. Summaries of the articles are translated into English.

The Journal will be divided into various sections including one devoted to articles concerning urgent issues in psychiatry, medical psychology and related problems of addiction, social psychology, sociology and other medical sciences and humanities. There will also be discussion, case history, research review, short communication and book review sections.

The Editor-in-Chief is Dr Yuri V. Popov, V.M. Bekhterev Psychoneurological Research Institute, 3 Bekhterev Street, 193019 Leningrad, USSR.

\title{
Facilitating moves into the community: a new mental health services initiative
}

\author{
Rosalind RamSAY, Registrar in Psychiatry, The Middlesex Hospital, London WIN 8AA
}

Stephen Dorrell, the government Health Minister, has criticised the current "gross misallocation" of resources for patients with mental illness. The Department of Health estimates that more than half the district health authorities' budget of $£ 1.5$ billion for mental health services is still being channelled into the 90 remaining large specialist mental hospitals. There are now only 40,000 patients in such institutions. However, according to government calculations, a total of $2 \frac{1}{4}$ million people in this country have a mental illness which is "serious enough" for them to need consultant psychiatrist care. All those sufferers from mental illness living in the community must make do with the remaining DHA budget. In other words, $98 \%$ of the mentally ill are supported by less than half the total resources allocated by districts for mental health services.

As a preliminary measure to try and release resources at present tied up in the old asylums, in 1990 , the government introduced the Capital Loans Fund which gives bridging finance to health authorities wishing to switch to more community based facilities. Regional health authorities have, however, continued to encounter difficulties in the move away from providing hospital based services for the mentally ill, and have identified the lack of appropriate management skills and experience as two of the major obstacles to developing more locally run services which could offer care within the community.

One initiative to help overcome this problem is the new Centre for Mental Health Services Development.
This is an NHS management consultancy set up in April under the auspices of the Institute of Health at King's College, London, and jointly funded by the Mental Health Foundation and, for the first three years, the Department of Health. The staff include a mixture of mental health service managers and clinicians with first hand experience of implementing locally based mental health services. The centre's brief is to advise health authorities on how they may best go about achieving a radical switch in resources from the old psychiatric hospitals to newer facilities for mental health care within local communities. In the future, drawing on its accumulated experience in the development of specific mental health programmes, the centre will be in a position to contribute to national plans for improving services throughout the country.

More specific objectives are to identify and find solutions for some of the problems associated with the closure of long stay institutions and assist with the transition phase of moving patient care into local communities as well as facilitating the planning and management of locally based services. The staff are hoping to pilot new models of service provision which may challenge traditional patterns of care but will be both more tailored to local needs and also affordable. Underlying the centre's policy is a clear philosophy of treating the service user as a "valued citizen with rights, responsibilities and requirements", entitled to "have an active opportunity to shape and influence services no matter how severe his or her distress". 